\title{
Enhanced technology of phytoremediation
}

\author{
Cui Shuang, ${ }^{1, *}$, Han Qing ${ }^{2}$, Bai Song ${ }^{1}$ \\ ${ }^{1}$ College of Environmental and Chemical Engineering, Shenyang Ligong University, Shenyang, Liaoning, 110159, China \\ ${ }^{2}$ School of Materials \& Metallurgy, Northeastern University, Shenyang, Liaoning, 110819, China
}

\begin{abstract}
The enhanced technology of phytoremediation has the advantages of low treatment cost, good purification effect, low environmental risk and environmental aesthetics. However, some hyperaccumulators grow slowly and their biomass is generally low; the activity of heavy metals in the soil is very low; the roots of plants are distributed in the surface of the soil, and the remediation effect of deep soil is poor; the nutrients of the soil to be repaired are seriously insufficient. It is necessary to take a series of strengthening measures to improve the efficiency of phytoremediation. The strengthening technologies of phytoremediation include chemical strengthening, microbial strengthening, animal strengthening, carbon dioxide strengthening, agronomic and management measures strengthening, etc.
\end{abstract}

\section{Introduction}

Phytoremediation refers to the use of green plants to transfer, accommodate or transform heavy metal pollutants, removing them from the environment or making them to become harmless substances. Phytoremediation can not only repair heavy metal pollution, but also the pollution of soil and water caused by organic matter or radioactive elements. The main principle is plant fixation and plant extraction. The basic strategy of plant fixation is to plant plants with high concentration and strong tolerance to heavy metals in contaminated soil. Plant extraction is to use the root tissue of plants to absorb heavy metals in soil, so that heavy metal pollutants can be transferred to the ground. Through continuous harvesting of the aboveground parts of plants, the content of heavy metals in the soil can be reduced, reaching the goal to purify the pollutants in soil or water and repair the heavy metal pollution in soil.

Phytoremediation is an environmental protection and green remediation technology, which is no secondary pollution, easy operation and low cost [1]. The disadvantages includes the plant growth speed is slow, the biomass is not high, and the accumulation of heavy metals is limited. In addition, the plant growth also has regional characteristics, which limits the wide application of phytoremediation. How to increase the uptake of heavy metals by plants, improve the survival ability of plants in areas with high degree of heavy metal pollution, and improve the biological characteristics of plants is a problem that can not be ignored in phytoremediation of heavy metal contaminated soil.

\section{Chemical enhanced method}

Chemical strengthening is mainly reflected in two aspects: one is to use chemical substances to change the form of heavy metals, so as to transform them from bound state to water-soluble exchange state, improve their bioavailability, thus improving the efficiency of phytoremediation; the other is to improve the biomass of plants (especially the aboveground part), so as to increase the total absorption of target heavy metals by plants [2]. In the technology of chemical enhanced soil remediation, chelating agents are used most, followed by surfactants, acid-base regulators and plant hormones [3].

\subsection{Acid and alkali regulator strengthening}

The $\mathrm{pH}$ of soil affects the plant growth, the dissolution and precipitation balance of heavy metal compounds, and the existence of heavy metals, thus affecting the effect of plant restoration. The adsorption of most heavy metals in soil solid phase decreases with the decrease of $\mathrm{pH}$ of soil solution [2]. The reduction of $\mathrm{pH}$ value can be realized by adding acid or fertilizer directly, such as adding dilute sulfuric acid and applying ammonium solid fertilizer. Mahler et al. [4] showed that lettuce and beet grew in $\mathrm{pH}$ 4.8-5.7 soil, which could absorb Cd better than lime soil with $\mathrm{pH}$ 7.4-7.8. Tyler et al. [5] studies found that the release of heavy metals in soil increased with the decrease of $\mathrm{pH}$, and $85 \% \mathrm{Cd}$ was released when $\mathrm{pH}$ was 2.8. Meanwhile, for the plants with super enrichment which need neutral or alkaline soil conditions, the $\mathrm{pH}$ value of soil increased by adding $\mathrm{CaO}$ or nitrogenous fertilizer. Liao et al. [6] studied the effect of soil $\mathrm{pH}$ on the effectiveness of cadmium. The content of available cadmium increased with the increase of $\mathrm{pH}$

\footnotetext{
*Corresponding author: ccshuang@163.com 
when $\mathrm{pH}$ was less than 6 , and the content of effective cadmium decreased with the increase of $\mathrm{pH}$.

\subsection{Surfactant strengthening}

Surfactants have been widely used to control environmental pollution because of their hydrophilic and lipophilic amphiphilic properties. The feasibility of using surfactants to enhance plant extraction of heavy metals from soil is based on the relationship among surfactants, heavy metals, soil and plants, When the concentration of surfactant exceeds the critical micelle concentration, micelles are formed in the solution, and the heavy metals in the solution are removed by electrostatic adsorption and ultrafiltration. The relationship between surfactant and soil is determined by ultrafiltration technology and the experimental results of $\xi$ potential, that is, after the adsorption at the soil interface and metal association, the relationship between surfactant and soil is determined. The theory of cell membrane permeability reveals the relationship between surfactants and plants, that is, surfactants change the structure and permeability of biofilm and promote the absorption of heavy metals by plants. The development of environmentally friendly biosurfactants is the frontier direction in this research field [7]. The principle of enhancing phytoremediation by surfactants is to promote the absorption of pollutants of plants by changing the structure and permeability of cell membrane [8]. Luo et al. [9] studied the effects of three surfactants on remediation of cadmium contaminated soil by wheat under hydroponic conditions, and found that the three surfactants could significantly increase the cadmium content absorbed by wheat, and CTAB was the best.

\subsection{Phytohormone fortification}

Plant hormone is a kind of trace substance which is synthesized in plants and regulates the growth and development of plants. They include ethylene (ETH), indoleacetic acid (IAA), cytokinin (CTK) and gibberellin (GA). In view of the toxicity of chelating agents to plants, phytohormones can be added to alleviate heavy metal stress, promote plant growth and enhance the ability of phytoremediation. Zhang et al. [10] studied the effect of combined application of plant hormones IAA, and $\mathrm{GA}_{3}$ on the remediation of heavy metal cadmium pollution in rape by pot experiment. The results showed that plant hormones could alleviate the stress of cadmium on rape in soil. Under the same treatment, $\mathrm{GA}_{3}$ was better than IAA. Li et al. [11] studied the effect of chelating agents EDTA and IAA on the remediation of cadmium contaminated soil. When EDTA-IAA was combined, the extraction efficiency of $\mathrm{Cd}$ from aqueous solution increased by about $39 \%$.

\subsection{Chelating agent strengthening}

The common artificial chelating agents include: ethylenediamine tetraacetic acid (EDTA), ethylenediamine disuccinate (EDDS), aminotriacetic acid (NTA), diethyltriamine pentanoic acid (DTPA), etc. The mechanism of phytoremediation enhanced by chelating agents is manifested in soil and plant. Soil action process refers to chelating agents promoting the desorption and release of heavy metals from soil particles into soil solution, increasing the probability of plants absorbing heavy metals; plant action process includes enhancing the tolerance of plants to heavy metals and promoting the transport of heavy metals to aboveground plants. Chelation induction not only depends on plant species and heavy metal types, but also closely related to the physical and chemical properties of soil and the use of chelating agents [3].

Luo et al. [12] studied the enhanced effect of EDTA, EGTA and CA on the absorption and enrichment of cadmium in Populus alba through pot experiment, and found that Populus alba has strong tolerance to the interaction of cadmium and chelating agents. These three chelating agents significantly increased the concentration of water-soluble cadmium in soil, and increased the transfer coefficient of cadmium in Populus alba. The accumulation of cadmium in leaves of Populus alba is 1.42 2.77 times of the control group.

Ethylene diamine tetraacetic acid (EDTA), ethylene glycol bis tetraacetic acid (EGTA), N-hydroxyethyl ethylenediamine triacetic acid (HEDTA) and other chelating agents are widely used in the remediation of heavy metal contaminated soil [13]. However, the biodegradability of these chelating agents is poor, and it is easy to leach heavy metals, which may cause the secondary pollution of surface water and groundwater. Therefore, the research and development of biodegradable chelating agents is a hot topic in this field research hotspot [14]. The main biodegradable chelating agents for phytoremediation are amino carboxylic acid chelating agents and organic phosphonic acid chelating agents.

EDDS (ethylenediamine succinic acid) is an easily biodegradable amino carboxylic acid chelating agent. EDDS has strong chelating ability, which can effectively increase the activity of heavy metals in soil, make it easy to be absorbed by plants, and effectively improve the efficiency of phytoremediation [15]. EDDS is produced by microorganisms with low toxicity. It can be completely degraded in various environmental media within 5-8 days, and the degradation products are harmless, and the impact on soil microorganisms and fungi is relatively little [16]. Zhong et al. [17] compared the effects of different concentrations of EDDS and EDTA chelation on the extraction of copper, zinc, lead and cadmium from soil with Indian mustard as a phytoremediation plant. The results showed that EDDS had a stronger activation effect on copper and zinc, while EDDS had a weaker effect on the extraction of ammonium nitrate. Luo et al. [18] used EDDS to chelate and extract heavy metals from stream sediments. When the treatment time was $24 \mathrm{~h}$, the removal rates of copper, zinc, cadmium and lead increased significantly, and the removal rates of various heavy metals increased with the increasing of the molar ratio of chelating agent to heavy metals. 
Nitrilotriacetic acid is also a kind of degradable amino carboxylic acid chelating agent. Its degradation rate is very fast under low temperature and anaerobic conditions, and its half-life in soil is 3-7 days [19]. NTA can effectively enhance phytoremediation of heavy metal contaminated soil, but NTA is selective for heavy metal activation. NTA can promote the uptake of $\mathrm{Cu}, \mathrm{Zn}, \mathrm{Cd}$, $\mathrm{Pb}$ and other heavy metals by hyperaccumulators. Kulli et al. [20] studied the effect of NTA on the remediation of $\mathrm{Cd}, \mathrm{Cu}, \mathrm{Zn}$ contaminated soil by Geba and ryegrass. The results showed that the contents of three heavy metals in the aerial parts of the two plants were significantly higher than that of the control. Apostolos et al. [21] applied NTA to remediate cadmium contaminated soil, which showed that the removal rate of cadmium by NTA was higher than that by DTPA and EGTA. Zhou et al. [22] studied the effect of NTA on the remediation of $\mathrm{Zn}, \mathrm{Cu}$ contaminated soil by maize. When the concentration of NTA was $10 \mathrm{mmol} \cdot \mathrm{kg}^{-1}$, the enrichment coefficient and transfer coefficient of $\mathrm{Zn}$ increased by 3.88 and 2.68 times respectively, while that of $\mathrm{Cu}$ increased by 4.75 and 2.28 times respectively.

Iminodiscucinic acid is a new type of biodegradable chelating agent, which can not only form chelates with metal ions, but also have good biodegradability [23]. Liu et al. [24] studied the effect of IDSA on phytoremediation of heavy metal pollution by greenhouse pot experiment. The results showed that the concentration of $\mathrm{Cd}$ in maize shoot was significantly higher than that in control, EDTA and EDDS treatment, and the concentration of $\mathrm{Cu}$ in maize shoot and root was significantly higher in IDSA treatment than that in control and EDTA treatment. The concentration of lead in the shoot of maize plants added with IDSA was significantly higher than that of the control.

Aspartic acid diethoxysuccinate (ASA) is a new type of green chelating agent with low nitrogen content and biodegradability [25]. Zhao et al. [26] compared and analyzed the effect of AES and EDTA chelation on Ryegrass remediation of cadmium contaminated soil by pot experiment. The concentration of $\mathrm{Cd}$ in the upper part of rye grassland was $1.57 \mathrm{mg} \cdot \mathrm{kg}^{-1}$, which was significantly higher than that of control and EDTA treatment. The results showed that AES could significantly promote the uptake of $\mathrm{Cd}$ in the upper part of rye grassland, and AES had great potential in inducing phytoremediation of $\mathrm{Cd}$ contaminated soil.

N,N-bis (carboxymethyl) glutamic acid tetrasodium has two enantiomers (L-form and D-form), and their biodegradation characteristics are different. In the OECD301D sealed bottle degradation test, the degradation rate of L-GLDA was more than $60 \%$ within 28 days, while D-GLDA was not easy to be biodegraded. Under the same conditions, the degradation amount was less than $10 \%$ after 80 days. Therefore, only L-GLDA can be used as a green chelating agent substitute. Compared with EDTA and other biodegradable chelating agents, GLDA has lower ecotoxicity [23]. Wei et al. [27] compared and analyzed the effect of GLDA and EDTA chelation strengthening hyperaccumulator Sedum alfredii on zinc cadmium compound pollution by pot experiment. The results showed that GLDA significantly increased the biomass of Sedum alfredii, and the accumulation of zinc and cadmium in Sedum alfredii under GLDA application was greater than that under EDTA treatment.

\section{3 microbial strengthening method}

Microorganisms in heavy metal contaminated soil can affect the migration and release of heavy metals in many ways. In practical application, we can use experiments to cultivate strains with growth advantages according to the demand. Hou et al. [28] studied the effect of dominant bacteria on the remediation of cadmium contaminated soil by Houttuynia cordata Thunb. The results showed that the concentration of cadmium in the aboveground part of Houttuynia cordata Thunb. increased 20 times than that of the control by adding the soil bacteria suspension cultivated by cadmium.

\section{Other strengthening measures}

The strengthening of agronomic measures is to maximize the biomass of restoration plants through reasonable water and fertilizer supply. Fertilizer application can change the environmental conditions of the soil surface, and provide nitrogen, phosphorus, potassium and trace elements for plants [10]. Chen et al. [3] studied the effect of nitrogen fertilizer on the growth and cadmium accumulation of Mirabilis jalapa by pot experiment, and found that nitrogen fertilizer can improve the biomass of Mirabilis jalapa and promote the absorption of cadmium. Compared with the control, the plant height increased by $8.6 \mathrm{~cm}$, and the cadmium content in shoot was $131.87 \mathrm{mg} \cdot \mathrm{kg}^{-1}$. The maximum cadmium transfer coefficient of Mirabilis jalapa was 2.57 .

Earthworms have a certain tolerance to heavy metals in contaminated soil, and affect the occurrence and bioavailability of heavy metals. Therefore, earthworms can also be introduced into phytoremediation to improve the efficiency of phytoremediation [29].

Carbon dioxide enhanced phytoremediation is to promote plant growth, improve plant biomass and induce plants to accumulate some heavy metals by increasing the concentration of carbon dioxide, so as to improve the efficiency of phytoremediation [30]. The increase of carbon dioxide concentration can also improve the bioavailability of soil nutrients. Studies have shown that doubling $\mathrm{CO}_{2}$ concentration can increase plant yield by about 30\% [31].

\section{Conclusions and prospects}

The plants with fast growth, deep-rooted and easy accumulation of target metals should be used in phytoremediation. Phytoremediation has the advantages of wide application range, low cost and in-situ remediation. It is a new, potential and developing green treatment technology to remove environmental pollution, and also a promising technology to repair heavy metal 
contaminated agricultural land. However, phytoremediation has many problems, such as low efficiency and long cycle. By a variety of strengthening technologies, the efficiency of soil pollution remediation can be improved, but there are still many shortcomings, which need to be strengthened through a variety of technologies.

\section{Acknowledgements}

This work was financially supported by National Natural Science Foundation of China (41773093).

\section{References}

1. Z.C. Liu, B.N. Chen, L.A. Wang, O. Urbanovich, L. Nagorskaya, X. Li, L. Tang. J. Hazard. Mater., 400, 5 (2020)

2. S.Y. Dong, Chongqing: Southwest Agricultural University (2003)

3. J. Chen, Anhui Agr. Sci., 38, 24 (2010)

4. R.J. Mahler, F.T. Bingham, A.L. Page, et al. J. Environ. Qual., 11, 4 (1978)

5. G. Tyler, Water Air Soil Poll., 9, 2 (1978)

6. M. Liao, Acta environ. Sin., 9, 1 (1999)

7. Y. C. Chen, S.L. Xiong, Z.T. Xiong, J. ecol. environ., (2004)

8. X. Xiong, Guangzhou chem. Ind., 40, 13 (2012)

9. L.X. Luo, T.Q. Sun. Acta ecol. Sin., 9, 1 (1998)

10. T. Zhang, Xiamen: Jimei University (2012)

11. B. Li, Changsha: Hunan University (2010)

12. H.Z. Luo, Z.R. Nan, Y.H. Hu, et al. Chin. Environ. Sci., (2013) 33, 3

13. Z.H. Ding, X. Hu, D.Q. Yin, Acta ecol. Sini., (2009) 18,2

14. F.X. Chen, M. Heus, T. Minshull, Chin. detergent indus., 2 (2010)

15. R.Q. Chen, Printing and dying, 8 (2001)

16. Z.Y. Pu, Y.H. Huang, S. Pu, et al. Progress in textile Sci. Tech.,6 (2006)

17. C.J. Zhong, Chongqing: Southwest Agricultural University, 2004

18. L.J. Luo, X. Hu, Acta Agri. Sin., 27, 3 (2008)

19. R.Q. Chen, Printing and dyeing, 19 (2010)

20. B. Kulli, M. Balmer, R. Kerbs, et al. J. Environ. Qual., 28, 6 (1999)

21. G. Apostolos, N. Aris, P. Despina, et al. Environ. Poll., 157 (2009)

22. J.M. Zhou, Z. Dang, N.C. Chen, et al. Acta Agri. Environ. Sci., 26, 2 (2007)

23. H. Tang, M. Wang, Z.Z. Liu, et al. J. Shanghai Jiaotong Univer., 31, 2 (2013)

24. X.N. Liu, Beijing: China University of Geosciences, (2012)

25. S.H. Jiang, J.W. Xu. Chemical world, 3 (2013)
26. Z.Q. Zhao, M.Z. Xi, G.Y. Jiang, et al. Environ. Chem., 29, 3 (2010)

27. Z.B. Wei, Q.T. Wu, X.X. Long, et al. J. Agri. Environ. Sci., 33, 7 (2014)

28. L.L. Hou, R. Huang, L.R. Zhou, et al. Acta Ecol. Sini., 19, 4 (2010)

29. C.L. Chen, M. Liao. Guangdong trace element sci., 11,10 (2004)

30. S.R. Tang. Beijing: Science Press (2006)

31. X. Chen, D.X. Wu, G.X. Wang, et al. Acta Ecol. Sini., 11, 6 (2000) 